\title{
O 'paradoxo' da morfologia das línguas de sinais por Adam Schembri
}

\author{
Daltro Roque Carvalho da SILVA-JÚNIOR @ \\ Universidade Federal do Paraná (UFPR)
}

André Nogueira XAVIER (1)

Universidade Federal do Paraná (UFPR)

○

OPEN ACCESS

EDITADO POR

Raquel Freitag

AVALIADO POR

Anderson Almeida

SOBRE OS AUTORES

Daltro Roque Carvalho

da Silva-Júnior

Contribuiu com André Nogueira

Xavier. Papéis:

escrita - análise e edição.

André Nogueira Xavier Contribuiu com Daltro Roque Carvalho da Silva-Júnior. Papéis: escrita - análise e edição.

DATAS

Recebido: 08/08/2020 Aceito: $21 / 08 / 2020$ Publicado: 25/09/2020

COMO CITAR Silva-Júnior, D. R. C.; Xavier, A. N. (2020). O 'paradoxo' da morfologia das línguas de sinais por Adam Schembri. Revista da Abralin, v. 19, n. 2, p. 1-6, 2020.
RESUMO

Adam Schembri discutiu o conceito de complexidade morfológica nas línguas sinalizadas, bem como os paradoxos que resultam da análise dessas línguas à luz das visões de Aronoff, Meier e Sandler (2005) e de Trudgill (2011). Segundo o conferencista, os primeiros autores não definem tal conceito, mas pode-se depreender de seu trabalho que eles o associam à composição plurimorfêmica do sinal. Nessa perspectiva, o paradoxo da morfologia das línguas de sinais emerge do fato de essas línguas apresentarem uma mistura de características típicas de línguas polissintéticas e de línguas crioulas. Alternativamente, Trudgill define a complexidade morfológica com base nas dificuldades de aquisição enfrentadas por aprendizes adultos de línguas estrangeiras: a irregularidade, a imprevisibilidade dos alomorfes, a redundância e a marcação morfológica de categorias. Nessa perspectiva, o paradoxo da morfologia das línguas de sinais decorre da escassez dessas propriedades nessas línguas, ainda que apresentem construções morfologicamente complexas envolvendo verbos indicadores e classificadores.

\section{ABSTRACT}

Adam Schembri discussed the concept of morphological complexity in sign languages, as well as the paradoxes that result from the analysis of these languages in the light of the views of Aronoff, Meier and Sandler (2005) and Trudgill (2011). According to the speaker, the first authors do not define such a concept, but it can be inferred from their work that they 


\section{REVISTA DA ABRALIN}

associate it with the plurimorphic composition of the sign. In this perspective, the paradox of the morphology of sign languages emerges from the fact that these languages have a mixture of characteristics typical of polysynthetic and creole languages. Alternatively, Trudgill defines the morphological complexity based on the acquisition difficulties faced by adult foreign language learners: the irregularity, the unpredictability of allomorphs, the redundancy and the morphological marking of categories. In this perspective, the paradox of sign language morphology stems from the scarcity of these properties in these languages, even though they present morphologically complex constructions involving indicating verbs and classifiers.

\section{PALAVRAS-CHAVE}

Complexidade morfológica. Tipologia sociolinguística. Línguas de sinais.

\section{KEYWORDS}

Morphological complexity. Sociolinguistic typology. Signed languages.

Com base em Aronoff, Meier e Sandler (2005) e Napoli (2009), o Prof. Dr. Adam Schembri explica que o paradoxo da morfologia das línguas de sinais está no fato de que ela parece ser ao mesmo tempo complexa como a de línguas polissintéticas (e.g. o navajo) e simples como a de línguas crioulas (e.g. tok-pisin). Isso porque observam-se nas línguas de sinais, de um lado, a ocorrência de construções classificadoras formadas pela combinação de muitos morfemas e, de outro, a quase inexistência de processos afixais. ${ }^{1}$

O Prof. Adam destaca que, esse paradoxo, na visão de Aronoff, Meier e Sandler é decorrência de dois fatores: a modalidade de produção e percepção das línguas de sinais e de sua relativa juventude. Precisamente, ele diz que por serem visuais-gestuais, essas línguas podem explorar a simultaneidade e a iconicidade e assim desenvolver uma morfologia interna ao sinal mais complexa. Apesar disso, por serem, comparativamente às línguas orais, mais jovens - segundo ele a língua de sinais mais antiga deve ter cerca de 300 anos - as línguas de sinais ainda não tiveram tempo de desenvolver uma morfologia afixal via gramaticalização.

Embora Aronoff, Meier e Sandler, de acordo com o Prof. Adam, não tenham definido a complexidade morfológica, ele a associa à existência, na estrutura interna do sinal, de mais de um morfema, ilustrando-a por meio de uma forma do verbo indicador da língua de sinais britânica, BSL (do inglês British Sign Language), AJUDAR. Quando realizado com movimento partindo do interloculor na

\footnotetext{
${ }^{1}$ Tradução desta resenha em Libras disponível em: https://www.youtube.com/watch?v=kp0Tcu80NOU\&feature=youtu.be
} 


\section{REVISTA DA ABRALIN}

direção do sinalizante, essa forma significa 'você me ajuda', logo seria constituída por três morfemas, a saber, 2SG-AJUDAR-1SG.

Antes de explorar a juventude das línguas de sinais como um dos fatores que explicam o paradoxo da morfologia dessas línguas, o Prof. Adam a que aponta que essas línguas podem ser classificadas em três categorias: (1) línguas sinais estabelecidas e usadas por macro-comunidades; (2) língua de sinais estabelecidas e usadas por micro-comunidades e (3) línguas de sinais emergentes. Entre as primeiras ele inclui a BSL, a língua de sinais australiana, Auslan (do inglês Australian Sign Language) e a Libras. Já entre as segundas ele cita a língua de sinais Kata Kolok, usada na Indonésia, e a língua de sinais Adamorobe, usada em Gana. Por fim, entre as línguas de sinais emergentes o Prof. Adam menciona a língua de sinais nicaraguense e a cambodiana, ambas, segundo ele, em existência há poucas décadas.

Baseado em pesquisas sobre a língua de sinais nicaraguense, o Prof. Adam reporta que, apesar de não terem sido observadas modulações espaciais de certos verbos para a representação de seus argumentos na primeira geração de sinalizantes, isso foi atestado nas gerações seguintes (SENGHAS, 2003; MONTEMURRO et al., 2009). Em outras palavras, em pouco tempo, muito provavelmente por conta da iconicidade, esses verbos desenvolveram complexidade morfológica ao passarem a expressar por meio do ponto de partida de seu movimento seu sujeito e do ponto de chegada, o seu complemento. Ele destaca, entre esses usos, aqueles em que esses pontos não coincidem com entidades presentes no momento da sinalização e, consequentemente, apresentam pontos de partida e chegada associados a localizações laterais no espaço em frente ao corpo do sinalizante. Segundo o Prof. Adam, no entanto, estudos recentes sobre a BSL indicam que, mesmo sendo uma língua de sinais em uso há relativamente mais tempo, construções com sujeito e complemento fazendo referência a terceiras pessoas são frequentemente produzidas com movimento inicial partindo do corpo dos sinalizantes e não de uma localização no espaço de sinalização (FENLON; SCHEMBRI; CORMIER, 2018).

Em busca de uma caracterização mais precisa da complexidade morfológica, o Prof. Adam recorre ao trabalho de Trudgill (2011). Como parâmetros para a gradação dessa complexidade, o autor propõe, com base na dificuldade de aprendizagem de línguas estrangeiras por adultos, a irregularidade, a opacidade morfológica, ou seja, a imprevisibilidade de ocorrência de alomorfes, a redundância e, por fim, a marcação morfológica. Ele exemplifica a irregularidade e a imprevisibilidade de alomorfes com dados da língua atsugwei, falada no norte da Califórnia nos Estados Unidos. Percebe-se por esses dados que os verbos, a depender de sua classe, se combinam com diferentes afixos para marcar pessoas do discurso. Em relação à redundância, o Prof. Adam cita dados do flamengo, no qual se observa a ocorrência numa mesma frase de três morfemas se referindo ao sujeito da oração. Por fim, a marcação morfológica de categorias é exemplificada por meio de morfemas flexionais de gênero e tempo.

Em contraste com muitas línguas orais, o Prof. Adam ressalta que, em conjunto, as línguas de sinais, da perspectiva de Trudgill, não seriam morfologicamente complexas, dado que apresentam pouca irregularidade (como exemplo de irregularidade ele cita a forma negativa de alguns modais), pouca opacidade morfológica (como exemplo de imprevisibilidade de alomorfia, ele cita duas formas 


\section{REVISTA DA ABRALIN}

de DAR-ME em um dialeto da Auslan e reporta que um deles nunca pode ser usado quando o destinatário é a segunda ou terceira pessoa), redundância limitada (como evidência de ausência de redundância ele cita a não obrigatoriedade de marcação do plural em alguns sinais quando são acompanhados por um quantificador numeral) e pouca ou nenhuma marcação morfológica de categorias (ele evidencia isso ao dizer que não há marcação morfológica para gênero, tempo e voz nas línguas de sinais). Na visão do professor, essa constatação representa um outro paradoxo na morfologia das línguas de sinais, dado que, apesar de não apresentarem essas características, ainda assim elas apresentam construções morfologicamente complexas como aquelas que envolvem verbos indicadores e classificadores.

Como possível explicação para essas características morfológicas, o Prof. Adam, mais uma vez, recorre à tipologia sociolinguística proposta por Trudgill para as línguas do mundo. Segundo esse autor, as "características sociais distintivas das comunidades influenciam a natureza da gramática de suas línguas". Trudgill ainda propõe, segundo o Prof. Adam, que os elementos definidores de uma comunidade linguística são (1) o tamanho da sua população, (2) o grau de integração de suas redes sociais; (3) sua estabilidade social e, por fim, (4) o grau de contato com seus dialetos e com outras línguas. Como mostra o Quadro 1 a seguir, traduzido de um dos slides do Prof. Adam, as comunidades podem variar em função dos diferentes graus que apresentam para cada um desses fatores. Segundo o Prof. Adam, "A complexificação morfológica tende a ser encontrada em comunidades densas e pequenas nas quais há situações de contato linguístico estáveis (especialmente nas situações 1 e 2)".

\begin{tabular}{|l|c|c|c|c|c|c|}
\hline & $\mathbf{1}$ & $\mathbf{2}$ & $\mathbf{3}$ & $\mathbf{4}$ & $\mathbf{5}$ & $\mathbf{6}$ \\
\hline Tamanho & pequena & pequena & pequena & pequena & grande & grande \\
\hline Rede social & densa & densa & frouxa & frouxa & frouxa & frouxa \\
\hline Contato & baixo & alto & baixo & alto & baixo & alto \\
\hline
\end{tabular}

\section{QUADRO 1 - Tipologia sociolinguística Fonte: Traduzido de Schembri (2020)}

Dessa perspectiva, as comunidades usuárias de línguas de sinais, não se enquadram nas categorias 1 e 2. Na verdade, de acordo com o Prof. Adam, elas se caracterizariam por apresentar populações pequenas com redes sociais que variam em densidade. Do ponto de vista da sua estabilidade social, ele menciona que, por conta da inclusão educacional, a aquisição da língua de sinais, tipicamente realizada de criança para criança em ambiente escolar, está menos estável. Por último, o professor destaca altos níveis de contato com a língua oral majoritária.

Com isso, o Prof. Adam chama a atenção para o fato de que a situação sociolinguística das línguas de sinais usadas por macro-comunidades não encontra qualquer correspondente nas situações observadas entre as línguas orais. Segundo ele, essa situação decorre de toda uma história de opressão e marginalização sofrida pelas comunidades surdas em todo o mundo. Somando-se a isso, ele ressalta, ela traz consequências importantes para o processo de aquisição, bem como para as características gramaticais dessas línguas. 


\section{REVISTA DA ABRALIN}

A maior parte dos surdos adquire uma língua de sinais do contato com outras crianças surdas na escola primária, secundária ou, mais tardiamente, no início da vida adulta através do contato com outros surdos (EMMOREY, 2002; HALL et al., 2019). Dessa forma, junto com aprendizes e usuários ouvintes, eles constituem a maioria dos sinalizantes. Na visão do Prof. Adam, a aquisição atípica por indivíduos com os mais variados backgrounds pode ter restringido a complexidade morfológica das línguas de sinais, fazendo com que elas se mantivessem com menos irregularidades, pouca alomorfia imprevisível, pouca redundância e pouca marcação morfológica.

A nosso ver, a discussão do Prof. Adam sobre os possíveis fatores responsáveis pelos dois paradoxos da morfologia das línguas de sinais pode ser interpretada como mais evidências de que as línguas são sistemas adaptativos complexos (SAC), ou seja, sistemas que, além de não-lineares, autorregulados e adaptáveis às respostas do ambiente, são resultantes da interação de muitas variáveis (LARSEN-FREEMAN; CAMERON, 2008). Dessa perspectiva, as línguas envolvem múltiplos agentes - o falante e a comunidade de fala, que interagem entre si - e o falante, por sua vez, se comporta com base em suas interações passadas e presentes e por influência de fatores que competem entre si e abrangem desde restrições perceptuais até motivações sociais (BECKNER et al., 2009, p. 1-2). Nesse sentido, podemos interpretar a modalidade de produção e percepção, a idade e a tipologia sociolinguística das línguas de sinais como conjuntos de variáveis de cuja interação emergem as características morfológicas enumeradas pelo Prof. Adam à luz dos trabalhos de Aronoff, Meier e Sandler e de Trudgill.

\section{REFERÊNCIAS}

ARONOFF, M.; MEIR, I.; SANDLER, W. The paradox of sign language morphology. Language, 81(2), p. 301-344, 2005. DOI: $\underline{10.1353 / \operatorname{lan} .2005 .0043}$

BECKNER, C.; ELLIS, N. C.; BLYTHE, R.; HOLLAND, J.; BYBEE, J.; KE, J.; CHRISTIANSEN, M. H.; LARSEN-FREEMAN, D.; CROFT, W.; SCHOENEMANN, T. Five Graces Group. Language is a complex adaptive system: Position paper. Language Learning, 59(Suppl 1), p. 1-26, 2009. DOI: $10.1111 /$ j.1467-9922.2009.00533.x

EMMOREY, K. Language, Cognition and the Brain: Insights from Sign Language Research. Mahwah, NJ: Erlbaum, 2002.

FENLON, J.; SCHEMBRI, A.; CORMIER, K. Modification of indicating verbs in British Sign Language: A corpus-based study. Language, 94(1), p. 84-118, 2018. DOI: 10.1353/lan.2018.0002

HALL, M. L.; HALL, W. C.; CASELLI, N. K. Deaf children need language, not (just) speech. First Language, 39(4), p. 367-395, 2019. DOI: $10.1177 / 0142723719834102$

LARSEN-FREEMAN, D., CAMERON, L. Complex systems and applied linguistics. Oxford: Oxford University Press. 2008.

MONTEMURRO, K.; FLAHERTY, M.; COPPOLA, M.; GOLDIN-MEADOW, S.; BRENTARI, D. Grammaticalization of the body and space in Nicaraguan Sign Language. In: Boston University Conference on Language Development, 43 ${ }^{\circ} 2019$. Somerville, MA. Proceedings... : Somerville: Cascadilla Press, 2019. p. 415-426. http://www.lingref.com/bucld/43/BUCLD43-33.pdf

NAPOLI, D. J. Morphological theory and sign languages. In: AUDRING, J.; MASINI, F. (Orgs.). The Oxford Handbook of Morphological Theory. Oxford: Oxford University Press, 2019. p. 594-614. DOI: 10.1093/oxfordhb/9780199668984.013.37 


\section{REVISTA DA ABRALIN}

ON understanding the 'paradox' of sign language morphology. Conferência apresentada por Adam Schembri [s.l., s.n], 2020. 1 vídeo (1h 30min 05s). Publicada pelo canal da Associação Brasileira de Linguística. Disponível em: https://www.youtube.com/watch?v=XqGWPAHZUKU. Acesso em: 02 ago 2020.

RIDDLE, E. M. Complexity in isolating languages: Lexical elaboration versus grammatical economy. In: MIESTAMO, M.; SINNEMÄKI, K.; KARLSSON, F. (Orgs.). Language complexity: Typology, contact, change. Amsterdam: John Benjamins, 2008 , p. 131-151. DOI: $\underline{10.1075 / \text { slcs.94.09rid }}$

SENGHAS, A. Intergenerational influence and ontogenetic development in the emergence of spatial grammar in Nicaraguan Sign Language. Cognitive Development. 18:4, p. 511-531, 2003. DOI: 10.1016/j.cogdev.2003.09.006

TRUDGILL, P. Sociolinguistic typology: Social determinants of linguistic complexity. Oxford: Oxford University Press, 2011. 